\title{
Opinion on the new financial products issued by financial institutions - structured products
}

\author{
Laurentiu Paul BARANGA \\ The Bucharest University of Economic Studies, Bucharest, Romania \\ barangalp@yahoo.com
}

\begin{abstract}
Structured products are financial instruments issued by a financial institution where the amount claimed by the investor from the issuer depends on the variation of the price of the underlying instrument based on which the certificate is issued, namely: individual shares, share costs, stock indexes, currencies, commodities or combinations of these according to the prospectus. These products appeared with the development and diversification of financial services during the recent years, as well as due to the emergence of liquidity suppliers of international importance. The liquidity providers have developed on their own platforms a new range of derivatives which are different from the classical derivatives. These new derivatives, similar to contracts for difference (CFDs), have given to other institutions the possibility of transferring their risk more easily, regardless of the nature or type of the underlying asset. Thus, the financial institutions issuing structured financial products have found in liquidity providers the possibility of developing the CFDs required for their risk transfer operations. The issuers of structured products do not accept new risky positions when they issue certificates because they neutralize them through suitable risk transfer operations. The issuing financial institutions structure certificates from a variety of financial assets and/or commodities in order to adjust them to the various risk profiles of investors both in terms of expected return and in terms of the response to risk. Thus, products are issued that quickly respond to the trends of the financial or commodity markets. Investors in structured financial products benefit from the economic effect of a derivative but are exposed to financial risks that are more complex and more difficult to understand and at the same time depend on the reliability and stability of the contractual relationships between various financial institutions.
\end{abstract}

Keywords: hybrid financial products, structured products, certificates, derivative.

\section{Introduction to structured products}

Structured products are a financial investment where the amount paid by the investor is exposed to various fluctuations of the reference value or of the performance of one or more assets/commodities that are indirectly purchased by that investor.

Structured products are traded according to the same rules as securities and the maximum possible loss an investor can experience is limited to the size of the original investment. Also, although structured products are considered to be debentures, they do not display all the features of bonds because they use non-standard cash flows determined by taking into account the evolution of the price or value of an underlying asset. Considering this feature, structured products are considered to be hybrid financial instruments between a zerocoupon bond and an option. 
At the same time, these structured products, although they include a component that is specific to derivatives, capable of changing the risk profile and the return, are different from these because they do not use guarantee mechanisms/margins specific to derivative transactions and the loss is limited.

If we refer to the rights of the holder of a structured product, he has a claim right against the issuer, the dynamics of the size of such claim being correlated to the variation of the price or value of the underlying asset. At the same time, if we refer to the dynamics of the size of the claim, it depends on the appreciation/depreciation speed of the price of the underlying asset as compared to the investor's type of position.

Functionally speaking, the issue price of a structured product can be considered as the value of a "financial services package" offered by the issuing financial institution, which includes both the required guarantees and all the costs, direct and indirect, relevant to the opening and closing of positions on the underlying assets included in the package. By including the costs of closing the initially opened positions in the price of the "financial services package", the maximum potential loss of the customer is limited to the value of the initial investment.

\section{When can structured products be issued?}

A financial institution may issue structured products only if it can meet several conditions, namely:

- $\quad$ it meets the legal requirements for becoming an issuer and is a participant in a trading venue;

it may become a market maker - the issuing financial institution will become a market maker for those products.;

there must be a possibility to transfer the financial risks relevant to structured products by opening positions on derivatives the underlying asset of which is the same item that determines the economic effect of those products;

it must enter into contractual relationships with one or several liquidity providers who give the financial institution the possibility to transfer at any moment its financial risks relevant to the structured products it has issued.

With respect to the stages that must be completed, after issuing the structured products, the issuer lists them in a trading venue and subsequently sells them to investors. For any long/short structured product sold, the issuer opens long/short positions on the underlying asset of that product on the platform of a liquidity provider. The issuer finances the opening of positions on the underlying asset until the value of the base price of the structured product is reached, which leads to the occurrence of the leverage effect. Thus, by buying a structured product the investor pays only the difference between the current price of the underlying asset and the base price of the product.

If we consider structured products as "standardized packages of financial services" intended for investors in order to obtain a leveraged exposure on a certain underlying asset (compared to derivatives) the role of the central counterparty and of the futures market is taken over by the liquidity provider with whom the issuer collaborates in view of achieving the risk transfer. 
To that effect, the counterparty's guarantee system is replaced with the margins requested by the liquidity provider for opening new positions on CFDs and with its own funds. Also, the trading rules relevant to a classic futures market are replaced by the liquidity provider's rules when offering new positions on CFDs that are necessary to the issuer in order to achieve the risk transfer.

Under these circumstances, besides the level of the liquidity provider's prudential ratios we must also take into account the circumstances under which the liquidity provider will respond to the issuer's requests of opening new positions on his platform, which are needed in order to achieve the risk transfer.

As a result of these vulnerabilities, we must take into account the contractual provisions that could impose a regime different from that of a classical futures market, namely: fees/number of contracts, maximum number of contracts, when and for how long they can change the level of the offered quotations, whether and when they may suspend the agreements signed with financial institution customers, under what circumstances the liquidity provider is held responsible for the loss experienced by a financial institution because it failed to offer or suspended the quotations, etc.

In other words, as a result of the liquidity provider's cumulation of both the role of a central counterparty and the role of a futures market operator, certain vulnerabilities occur regarding the provider's capacity to fulfil its obligations, as well as regarding the compliance with all the rules by virtue of which it offers new quotations on its own trading platform.

\section{Risk management at the structured products issuer level}

The following aspects are contemplated in risk management operations connected to structured products: the net daily exposure for each underlying asset that the economic effect depends on; the variation of the price/value of each underlying asset; the variation of the exchange rate; the variation of the risk-free interest rate, etc.

Therefore, for all the structured product categories, the issuer determines at the end of each trading session the net position between long positions and short positions. The net position is calculated for the structured products sold during that trading session and is provided separately for each category of structured products (with the same underlying asset) in order to determine the size of the exposure the issuer has regarding a certain asset. Thus, to achieve the risk transfer, the issuer opens, at the end of the structured products trading session, positions that are equal and opposite to his position on derivatives, that have the same underlying assets as the sold products.

The exposure is determined by multiplying the number of positions sold/to be redeemed by the price and level of the leverage effect of the product. The level of the leverage effect is one of the factors taken into account when determining exposure because the dynamics of the products is given by this factor, established for each separate category of products and highlighted in their issue prospectus.

The risk transfer operation contemplates all the types of financial risks the issuer is exposed to at the end of the structured products trading session, and among these risks counts the position risk relevant to the underlying asset, the foreign exchange risk resulting from the 
fact that the product is traded in a currency different from the currency used in the risk transfer operations, the interest rate risk, etc.

\section{Legislation on capital adequacy}

Regulation (EU) No. 575/2013 on capital adequacy refers to the determination of the capital requirement relevant to the position risk by dividing financial instruments into three categories, namely: capital securities, debt instruments, and units.

There are no structured products among the financial instruments included in the three categories, although their price depends on the dynamics of the price or of the value of the underlying assets, which in their turn are affected by the volatility of the market price.

At the same time, the legislation on capital adequacy includes a set of risk assessment rules and techniques in order to identify and highlight all the factors and vulnerabilities that influence the performance of financial assets within the portfolio of a financial institution. Thus, the standardized model of capital adequacy was built so as to take into account, throughout the capital adequacy rate determination stages, the market volatility, the negative correlations between assets, the risk transfer techniques, as well as the existence of capital reserves/buffers.

Thus, in the assessment of the capital requirement relevant to the position/market risk, the following aspects were also taken into account:

the market factor regarding which the volatility of the position held in the portfolio is determined (e.g.: price of securities, interest rate level).

the situation in which a financial instrument is affected by a mix of factors. If the intention is to analyze the structure of a unit, the financial instruments composing it can be grouped into the three categories;

if the positions are covered - i.e. there are some hedging operations - the calculation of the capital requirement for the market risk takes into account the weighted position between the long and short positions on the same underlying asset;

the situation in which, due to some disturbances of the financial markets, the covered positions turn from a risk coverage operation into a speculative operation.

Considering the above, we believe that, if a financial institution issues financial instruments that are formally included in a category (e.g.: debentures), but the return of which depends on the performance or dynamics of the price of the underlying asset that belongs to another category (e.g.: capital securities), the financial risk must be assessed in consideration of the factors determining the economic effect, not in consideration of the class of financial assets in which that financial instrument is formally included.

By applying this rule, the principles taken into account when building the capital adequacy standardized model and the general risk management principles are observed, and at the same time the reports provide a more accurate image of the vulnerabilities and factors that influence the economic phenomenon within the financial institution. This way all the correlations and interdependencies between the positions held by the financial institution and implicitly the vulnerabilities that could occur due to the dynamics of financial markets are highlighted. 


\section{Aspects regarding the risks that investors are exposed to}

Considering the features of a structured product, investors in these products are exposed to a series of financial and operational risks, grouped into two categories: direct risks and indirect risks.

The category of direct risks includes both risks attached to the underlying asset and risks attached to the assessment/way the product is built. The risks attached to the underlying asset can be: i) the position or commodity risk attached to the underlying asset of the issued structured product; ii) the foreign exchange risk: due to the currency in which the structured product is traded, which can be different from the currency in which the underlying asset is traded; iii) the interest rate risk, due to the way the structured product is assessed.

The risks attached to the assessment/way the product is built can be: i) the price determination model - the determination model is a complex one and relies on the understanding of the option assessment models; ii) the payment of dividends relevant to the underlying asset and the residual maturity shortening may have an impact on the product value; iii) the leverage effect: given by the ratio between the product price and the exposure the holder of that structured product can get.

The category of indirect risks includes risks relevant to i) the issuer of structured products - investors in structured products are exposed to the issuer's credit risk; ii) the agreements between the issuer and other financial institutions, through which the economic effect of that structured product is built.

The agreements between the issuer and other financial institutions can pose the following risks: i) the legal/operational risk that can appear as a result of the failure to observe the agreements by the liquidity provider with whom the issuer collaborates in order to achieve the financial risks transfer; ii) the liquidity risk that can appear if the issuer must pay a larger sum to the liquidity provider in order to get an exposure larger than expected.

In the case of weighted derivatives settled through a central counterparty, investors were not exposed to the indirect risks of structured products because either they did not exist or they were managed by that central counterparty. Although investing in structured products generally exposes investors to the same risks as with derivatives, we cannot say that these would be riskier than derivatives. Also, as opposed to futures markets that have a low liquidity, the liquidity risk of the financial instrument is taken over by the issuer, who is also the market maker of the issued products.

If in the case of central counterparties there were special regulations by which the ESMA imposed a set of prudential requirements to ensure a suitable level of financial reliability of these entities, in the case of structured products there was no such regulation. We say that there is no such regulation because the reliability of the connections/agreements between financial institutions, which builds the economic effect of the structured product, is not analyzed at aggregate level by any supervisory authority.

To assess the architecture needed for building the economic effect of that product, both the reliability of the risk management system of each financial entity involved and the implications of the "cascade contagion" risk that can occur when an agreement is breached must be analyzed, and implicitly the issuer must bear all the potential losses occurring 
because of the exposure to the risks attached to the structured products that could no longer be transferred to another financial entity (liquidity provider).

The Delegated Regulation (EU) No. 1286/2014 of the European Parliament and of the Council on key information documents for packaged retail and insurance-based investment products (PRIIPs) imposes to the financial institutions issuing structured products the obligation of providing potential investors with a short description of the profile by using a

\section{PICBE | 6} systemic risk indicator, as well as an explanation of the relevant risks regarding the structured product, which are not properly reflected by that systemic risk indicator.

Considering that the applicable legislation does not stipulate any transparency requirements devolving on the issuers of structured products, namely to publish aspects regarding the architecture based on which the economic effect of the product is built, we believe that these aspects are necessary in order to allow the investors assess both the direct and the indirect risks of the issued structured products and, implicitly, to be able to determine the level of the "aggregate" risk characterizing the analyzed product.

By implementing the legislation on the EMIR, the European lawmaker intended to ensure, as much as possible, the weighting and settlement of derivatives through a central counterparty and, at the same time, to have the relevant information of transactions with such derivatives be reported to certain transaction registers. The purpose of these regulations was to ensure more reliability for the financial system both by ensuring as much as possible the weighting and settlement of transactions with derivatives and by ensuring a necessary and useful framework in view of assessing the exposures between financial institutions and implicitly of any potential risk of contagion.

Considering the objectives of the European lawmaker in drafting the legislation on PRIIP and EMIR and in order to ensure a better protection of retail investors, we believe that the introduction of an obligation for the issuing financial institution to maintain a capital buffer intended exclusively for covering any losses relevant to the structured products it has issued, should be considered.

\section{Impact of structured products on the derivative markets}

As a result of the diversification of the financial services during the recent years the financial institutions have been able to issue structured products that quickly respond to the trends of the financial or commodity markets. To that effect, structured products have been issued for a variety of financial assets and/or commodities with a view to adjusting them to the risk profiles of investors, both in terms of the expected return and in terms of the response to risk.

These new hybrid financial instruments provide investors with a viable alternative to the classical financial instruments since they can be quickly adapted to any new trend of the markets or of the risk profiles of investors. Thus, by means of the structured products, investors have access to a wide range of investment strategies that would otherwise remain inaccessible or impractical to them and high returns can be generated through the leverage effect.

At the same time, due to the way they are managed by their issuer, structured products have led, on the one hand, to a higher competition between derivative markets and OTC transactions and, on the other hand, to a higher complexity level of financial instruments. All 
these effects of the emergence of structured products have direct implications both on the supervisory and regulatory activities and on the low-liquidity financial instruments markets.

Also, due to the indirect investment nature, investors in structured products are exposed to financial risks that are more complex and more difficult to understand and therefore they need much more information to be able to assess the risks they get exposed to. As a result of this, in the future the emphasis will be placed on the provision of more and more relevant information through the communication channels of regulated markets on which the structured products are quoted.

\section{Similarities and differences between structured products and units}

Legally speaking, structured products are debentures and they are implicitly exposed to the issuer's default risk, whereas by issuing units, resources are collected to form an asset basket, which are recorded and managed separately from those of that investment fund's manager.

By choosing a structured product, investors are able to follow their own strategies depending on their expectations and risk appetite, whereas by choosing a unit the investor delegates the investment decision to the investment fund manager because it is him who decides how the available resources should be invested in accordance with the investment policy of the fund.

As regards the way the price is determined for the two categories of financial instruments, there are significant differences. While the assessment of structured products is more complex and is based on the option assessment models, the assessment of units is the ratio between the value of the managed assets and the number of the units in circulation. Also, the issuers of structured products do not charge any management fees as it happens with investment funds where the fund manager charges such a fee.

\section{Conclusions}

1. Considering the particularities of structured products and the fact that Regulation (EU) No. 575/2013 did not refer to structured products, we believe that the financial risks attached to these products must be assessed and managed considering the factors that determine their economic effect on the issuer, not considering the class of financial assets in which that particular financial instrument is formally included.

By applying this rule, the principles taken into account when building the capital adequacy model and the risk management principles are observed, and at the same time the reports provide a more accurate image of the vulnerabilities and factors that influence the economic phenomenon within the issuing financial institution. This way all the correlations and interdependencies between the positions held by the financial institution and implicitly the vulnerabilities that could occur due to the dynamics of financial market are highlighted.

2. Considering that the applicable legislation does not stipulate any transparency requirements devolving on the issuers of structured products, namely to publish aspects regarding the architecture based on which the economic effect of the product is built, we believe it is necessary that the transparency obligations be extended to these aspects as well. This is necessary in order to allow the investors to assess both the direct and the indirect risks 
of the issued structured products and, implicitly, to be able to determine the level of the "aggregate" risk characterizing the analyzed product.

3. At the same time, considering the objectives of the European lawmaker in drafting the legislation on PRIIP/EMIR and the particularities of structured products, in order to ensure a better protection of retail investors, we believe that the introduction of an obligation for the issuing financial institution to maintain a capital buffer intended exclusively for PICBE | 8 covering any losses relevant to the structured products it has issued, should be considered.

4. Also, due to the indirect investment nature, investors in structured products are exposed to financial risks that are more complex and more difficult to understand and therefore they need much more information to be able to assess the risks they get exposed to. As a result of this, in the future the emphasis will be placed on the provision of more and more relevant information through the communication channels of regulated markets on which the structured products are quoted.

\section{Bibliography}

Commission Directive 2006/73/EC implementing Directive 2004/39/EC as regards organisational requirements and operating conditions for investment firms and defined terms for the purposes of that Directive.

Commission Regulation (EC) No 1287/2006 implementing Directive 2004/39/EC as regards record keeping obligations for investment firms, transaction reporting, market transparency, admission of financial instruments to trading, and defined terms for the purposes of that Directive.

Directive 2004/39/EC on markets in financial instruments.

Directive 2013/36/EU on access to the activity of credit institutions and the prudential supervision of credit institutions and investment firms, amending Directive 2002/87/EC and repealing Directives 2006/48/EC and 2006/49/EC.

Regulation (EU) No 575/2013 on prudential requirements for credit institutions and investment firms and amending Regulation (EU) No 648/2012.

Regulation (EU) No 648/2012 on OTC derivatives, central counterparties and trade repositories (EMIR).

Regulation (EU) No 1286/2014 on key information documents for packaged retail and insurance-based investment products (PRIIPs).

Directive 2014/91/EU amending Directive 2009/65/EC on the coordination of laws, regulations and administrative provisions relating to undertakings for collective investment in transferable securities (UCITS) as regards depositary functions, remuneration policies and sanctions. 